\title{
Does Reading SoTL Matter?: Difficult Questions of Impact
}

\author{
Nancy L. Chick, PhD \\ Academic Director of the Taylor Institute for Teaching \& Learning \\ University of Calgary
}

After a recent keynote on publishing the scholarship of teaching and learning (SoTL), a faculty member asked me the important question about the impact of these publications. As closely as I can remember, she said, "In medicine, we know that journal articles don't affect practitioner practice. How is SoTL any different?" Indeed, the medical education community has been raising this issue for some time. For instance, Richard Smith (2006) doesn't mince words: “Journals are not good at getting doctors to change and improve their practice. Words on paper rarely lead directly to change" (p. 117). In her keynote at the 2008 conference of the International Society for the Scholarship of Teaching and Learning, Sue Clegg alluded to this research:

what we know about professional learning from the communities of practice and informal learning literature suggests that the peer reviewed papers have very little, if any, impact on practice. Indeed the origins of systematic review in medicine were in recognition of precisely this problem-we know that Doctors and school teachers don't read this stuff.

So this question of impact in SoTL is not new (Cross \& Steadman, 1996; Hutchings, Huber, \& Ciccone, 2011; Hutchings \& Shulman, 1999; Poole, 2007;). It's also not unimportant.

In the inaugural issue of Teaching E Learning Inquiry, Keith Trigwell (2013) builds on the research on how our approaches to teaching affect students' learning. This previous work concludes the following:

An approach to teaching in which teachers provoke discussion and debate, monitor students' changing understanding, and encourage students to question their own ideas (a Conceptual Change / Student-Focused [CCSF] approach) has been shown, in several studies, to be related to more deep approaches to learning being adopted by their students (Trigwell, Prosser \& Waterhouse, 1999; Gibbs \& Coffey, 2004). The same studies show that when teachers report that they focus, for example, on good presentation, covering the content, and providing a good set of notes (an Information Transfer / Teacher-Focused [ITTF] approach) their students are more likely to report adopting more of a surface or lower-quality approach to learning. ( p. 98)

He extends and builds on this research by situating SoTL within a syllogism. First, he finds that "those teachers reporting higher CCSF approaches to teaching are also the teachers who are more engaged with the Scholarship of Teaching and Learning" (p. 98). Then, given this relationship between these deeper approaches to teaching and 
engagement with SoTL, and "given the research showing relations between teaching and outcomes of learning, [then] the scholarly, inquiring, peer review, and shared aspects of their teaching are likely to be achieving the purpose of improving student learning" (p. 98). To simplify, teachers who do SoTL are more likely to improve their students' learning.

Trigwell's work here provides an answer to the question about the impact of doing SoTL on SoTL practitioners and their students' learning. That's no small matter. However, it doesn't address the question about the impact of reading SoTL, or the broader question about the impact on teachers who don't do SoTL. These are complex questions that are hard to answer with precision. But that doesn't mean they are unanswerable questions.

In the strategic plan for my teaching and learning institute, I wrote about "multiple degrees of engagement" as part of the "reach and impact" of SoTL (Chick, 2016, p. 10; see figure right). Noting that much of our SoTL-related programming targets practitioners or "producers of SoTL projects" (p. 10), I acknowledged that-for a variety of

Degrees of SoTL Engagement, Reach, \& Impact

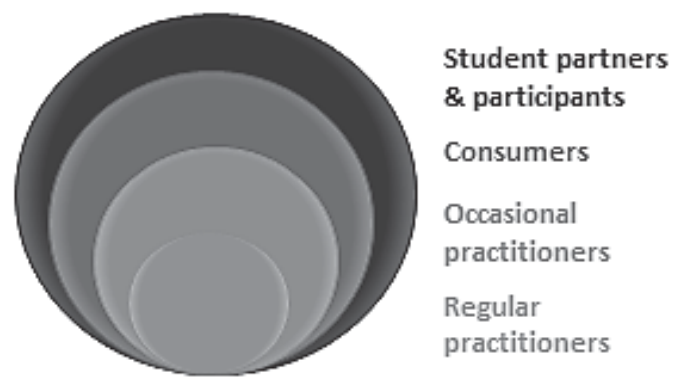
reasons - most of our colleagues won't do SoTL; however, their role as part of our teaching and learning community is no less important. Many of them are certainly scholarly teachers who care about their teaching and their students' learning and who intentionally strive to improve both. We can thus think of teachers who don't do SoTL as "potential consumers of SoTL":

at a department meeting, they'll learn about the findings of a colleague's project. In the copy room, they'll see someone printing the final draft of an article for publication. In the hallway, they'll overhear others talking about something they learned from the recent gathering of the SoTL Journal Club. Eventually, some of these bystanders will ask questions, enter into conversations, and learn from these SoTL-active colleagues. (p. 10)

Like all binaries, this distinction between producers and consumers can, of course, be problematic. There are grey areas, and consumers has some negative connotations and baggage that I don't intend to bring into this comparison (e.g., implications of passivity, corporatization). At some point, all metaphors are inherently wrong, but let's go with the useful implications for just a bit.

For this larger population of colleagues, I host a SoTL Journal Club that regularly discusses SoTL and SoTL-relevant texts. The faculty, staff, and occasional students who come to these meetings are rarely the same ones I see in SoTL workshops, writing retreats, and grant applications, and they often vary, depending on the selected readings. The discussions are largely participant-led, grounded in the reading, rich with connections to practice, and challenging to the readings, to each other, and to their assumptions and approaches. In some ways, I think these one-hour conversations make up the most important, most impactful SoTL work I do, despite the relatively 
small numbers. They range from 4 to 20 but typically fall in the middle. And it's not just that the participants differ from our regulars. It's the potential of what they do later.

According to Torgny Roxå and Katarina Mårtensson's research on the informal, "backstage" conversations about teaching that can happen in small networks (2009, 2011, 2015; Roxå, Mårtensson, \& Alveteg, 2011), the people who read the articles for the SoTL Journal Club may do something that can change individual approaches to teaching and the broader teaching cultures. When these SoTL readers have conversations with colleagues that are informed by these readings (e.g., at the Journal Club meeting, in the hallway, at the coffee counter, in a committee meeting), "teachers allow themselves to be influenced to such an extent that they develop, or even sometimes drastically change, their personal understanding of teaching and learning" (Roxå \& Mårtensson, 2009, pp. 547-548). And from Trigwell, Prosser, and Waterhouse (1999), we know that approaches to teaching affect student learning. Ultimately, that's the impact we want in SoTL. Yes, we want to affect practitioner practice-as the question at my keynote illustrated - but more importantly, we want to affect student learning.

But I hear you. You're absolutely right: this is a circuitous and messy path to trace impact, and the SoTL Journal Club numbers are very small - what some would call insignificant. This example is just that, an example. This small activity on one campus is metonymic, illustrative of the potential for all who read SoTL and SoTLrelated texts. When Teaching \& Learning Inquiry, the journal of the International Society for the Scholarship of Teaching and Learning (ISSOTL), moved out from behind the subscription firewall to fully open access, our readership increased. We know that the views and ...talk with others about what these readings make you think about. downloads of the article PDFs increased dramatically, as have the journal's citation alerts. (We don't yet have the exact numbers because of a few changes in platform, but we hope to have them soon.) Of course, we can't assume that people who view, download, or even cite an article read it, of course, but the chances are high that at least some of them do. So-like the research on open access in general ("Benefits for authors," 2017; Clements, 2017; Jump, 2014) -I'm saying that our readership increased but won't assert from this messy data by how much.

As you read the articles in this issue of InSight, you have this potential for impact as well. As you read and reflect on what you're reading, your understanding of and approach to teaching may change. And that may deepen your students' learning. And if you talk with some colleagues about the reading, or even just what you're thinking about related to the reading, their understanding of and approaches to teaching may change. And that may deepen their students' learning. So keep reading. And more importantly, talk with others about what these readings make you think about. You may-ultimately - be changing the world. 


\section{References}

Benefits for authors. (2017). Open Access at Nature Research. Retrieved from http://www.nature.com/openresearch/ab out-open-access/benefits-for-authors/

Chick, N. (2016). Taylor institute for teaching and learning scholarship of teaching and learning strategic plan: 2016-2019. Taylor Institute for Teaching and Learning. Retrieved from

http://www.ucalgary.ca/taylorinstitute/si tes/default/files/TI\%20SoTL\%20Strategic \%20Plan\%202016-19.pdf

Clegg, S. (2008, October 17). The struggle for connections. Keynote presented at the conference of the International Society for the Scholarship of Teaching and Learning Conference, Edmonton, AB, Canada. Retrieved from http://www.indiana.edu/ issotl/past_isso tl/2008proceedings.html

Clements, J. (2017, February 7). Open up! On the benefits of open access publishing. Canadian Science Publishing. Retrieved from

http://www.cdnsciencepub.com/blog/ope n-up-on-the-benefits-of-open-accesspublishing.aspx

Cross, K. P., \& Steadman, M. H. (1996). Classroom research: Implementing the scholarship of teaching. San Francisco, CA: Jossey-Bass.

Hutchings, P., Huber, M. T., \& Ciccone, T. (2011). The scholarship of teaching and learning reconsidered: Institutional integration and impact. San Francisco, CA: Jossey-Bass.
Hutchings, P., \& Shulman, L. S. (1999). The scholarship of teaching: New elaborations, new developments. Change: The Magazine of Higher Learning, 31(5), 10$15 . \quad$ Retrieved from http://www.tandfonline.com/loi/vchn20

Jump, P. (2014, July 30). Open access papers 'gain more traffic and citations.' Times Higher Education. Retrieved from https://www.timeshighereducation.com/ home/open-access-papers-gain-moretraffic-and-citations/2014850.article

Poole, G. D. (2007). Using the scholarship of teaching and learning at disciplinary, national and institutional levels to strategically improve the quality of postsecondary education. International Journal for the Scholarship of Teaching and Learning, 1(2). doi: 10.20429/ijsotl.2007.010203

Roxå, T., \& Mårtensson, K. (2009). Significant conversations and significant networks: Exploring the backstage of the teaching arena. Studies in Higher Education, 34(5), 547-559. doi: $10.1080 / 03075070802597200$

Roxå, T., \& Mårtensson, K. (2011). Understanding and influencing teaching and learning cultures at university: A network approach. Higher Education, 62(1), 99-111. doi: 10.1007/s10734-0109368-9

Roxå, T. \& Mårtensson, K. (2015). Microcultures and informal learning: A heuristic guiding analysis of conditions for informal learning in local higher education workplaces. International Journal of Academic Development, 20(2), 193-205.

doi: 
Roxå, T., \& Mårtensson, K., \& Alveteg, M. Trigwell, K. (2013). Evidence of the impact (2011). Understanding and influencing of scholarship of teaching and learning teaching and learning cultures at purposes. Teaching $\mathcal{E}$ Learning Inquiry, university: A network approach. Higher 1(1), 95-105. Retrieved from Education, 62(99), 99-111. doi: http://tlijournal.com/tli/index.php/TLI/art 10.1007/s10734-010-9368-9 icle/view/35

Smith, R. (2006). The trouble with medical journals. Journal of the Royal Society of Medicine, 99(3), 115-119. doi: 10.1258/jrsm.99.3.115

Nancy Chick is University Chair in Teaching and Learning, Academic Director of the Taylor Institute for Teaching and Learning, and Teaching Professor of English at the University of Calgary (Canada). She is also the founding co-editor of Teaching \& Learning Inquiry, the journal of the International Society for the Scholarship of Teaching and Learning (ISSOTL). 